\title{
Ten Percent Farm Tree Cover
}

\author{
Dickson N. Mukunga \\ Centre for Training and Integrated Research in ASAL Development (CETRAD), Nanyuki, Kenya \\ Email: dicksonmukunga@gmail.com
}

How to cite this paper: Mukunga, D.N. (2018) Ten Percent Farm Tree Cover. Open Access Library Journal, 5: e4677.

https://doi.org/10.4236/oalib.1104677

Received: April 23, 2018

Accepted: September 16, 2018

Published: September 19, 2018

Copyright $\odot 2018$ by author and Open Access Library Inc.

This work is licensed under the Creative Commons Attribution International License (CC BY 4.0).

http://creativecommons.org/licenses/by/4.0/

\begin{abstract}
Small scale farmers in arid and semi arid areas are working hard to be able to get output on their farms in the changing climate patterns. These patterns are characterized by short irregular rains and long drought spells. In order to mitigate climate changes there is need to plant trees. Trees trap carbon from atmosphere, trimmed to provide mulch and decompose to become manure. Data were collected through face to face interviews and descriptive analysis done. It was recommended that tree nurseries of drought resistant trees be established in the arid and semi arid areas to make seedlings available to the farmers.
\end{abstract}

\section{Subject Areas}

Agricultural Science

\section{Keywords}

Agroforestry, Farm Forestry, Ecosystem, Drought Resistant Trees

\section{Introduction}

Agroforestry is a collective name for land-use systems and technologies where woody perennials (trees, shrubs, palms, bamboos, etc.) are deliberately used on the same land-management units as agricultural crops and/or animals, in some form of spatial arrangement or temporal sequence. In agro forestry systems there are both ecological and economical interactions between the different components (Lundgren and Raintree, 1982) [1]. According to Kenya Agriculture (Farm Forestry) Rules [2], 2009 every agricultural land holding should have 10 percent (\%) farm forest cover. It is in line with the rules that farmers have been put to task to plant trees in their farms. There is a perception that trees "burn" crops growing near them, which has hindered farmers from planting trees on their farms. However, rather than threatening agriculture, 10 percent multipur- 
pose farm tree cover could reduce risk and provide greater opportunities for farm families and their local communities (Andrew Stewart and Rowan Reid) [1].

In addition, cultivating trees and agricultural crops in intimate combination with one another is an ancient practice that farmers have used throughout the world (P.K. Ramachandran Nair, 1993) [3]. This has seen farmers plant trees in lines on their farms and others designated plots for trees. Some species of trees are a source of fuel while others are a source of food (edible fruits). Farmers also are taking care of natural trees that have medicinal value. Indeed, agroforestry is fast becoming recognized as a land use system which is capable of yielding both wood and food while at the same time conserving and rehabilitating ecosystems (P.K. Ramachndran Nair 1993) [3].

\section{Methods}

The study was carried out at four divisions of KathonzweniSub-county. These divisions are Mavindini, Kathonzweni, Kithuki and Kitisewhich lies under arid and semi-arid lands (ASALS) characterized by low rainfall (Figure 1). There were 138 farmers who were interviewed. Figure 1 shows the study area.

Data were collected through face to face interviews using structured questionnaires and photography administered to households. Average per category of farmers were calculated and most commonly planted trees identified by sorting of the tree list. Data analysis was done through descriptive statistics where frequencies were computed. T-test was done to measure the significance using Statistical Package for Social Sciences (SPSS).

\section{Results}

Out of the 138 sampled famers, $69 \%$ interviewed were female and $31 \%$ male. Figure 2 shows gender distribution.

The six common trees amongst the farmlands were mangoes (Mangifera indica), pawpaw (Carica papaya), Mukengeta (Senna siamea), Muaa (Acacia tortilis), Mukau (Melia volkensii) and Mwaluvaini (Azadirachta indica). On average each household has 41 Mangifera indica trees, 16 trees of Carica papaya and Senna siamea types, 78 trees of Acacia tortilis, 13 trees of Melia volkensii and 4 trees of Azadirachta indica. Figure 3 shows the total sum of trees.

Figure 4 demonstrates T-test calculation results. Calculated value $-11.611<$ Critical value, 1.6561 hence we fail to reject the null hypothesis $\left(\mathrm{H}_{0}\right)$ and conclude that most farms in the study area do not have $10 \%$ tree cover.

Test value was arrived at after calculating the average acreage of farms of the household interviewed. In addition we also borrowed spacing from mango tree spacing which is $12 \mathrm{~m}^{2}$ (Jkuatenterprises pdfpge7) [4].

It is concluded that most farms do not have $10 \%$ tree cover since there are no inspection done by the ministry of agriculture. The few farmers who have attained $10 \%$ have been brought by the need to diversify their production thus planting fruit trees. 


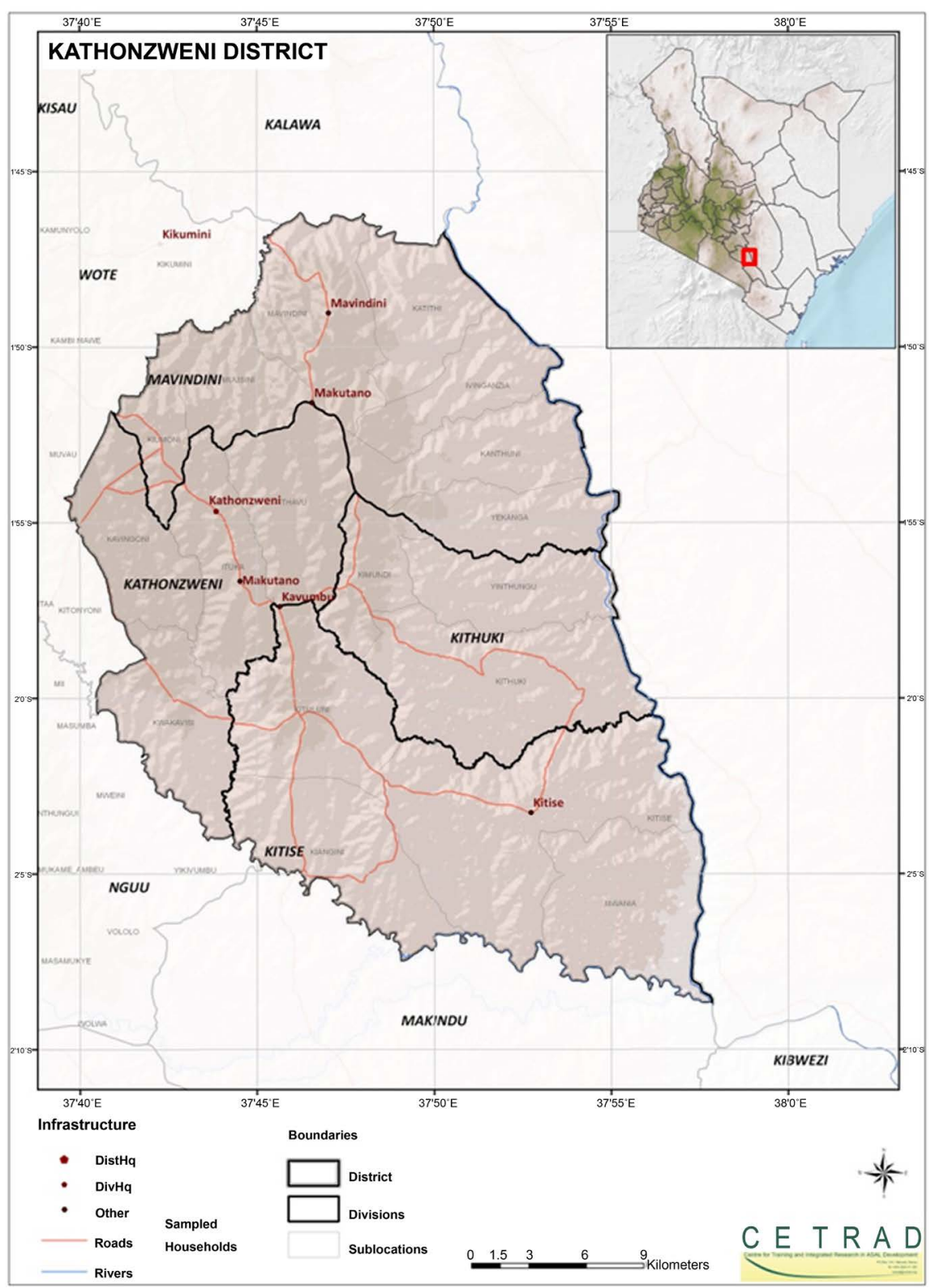

Figure 1. Map showing the study area (source CETRAD).

\section{Gender}

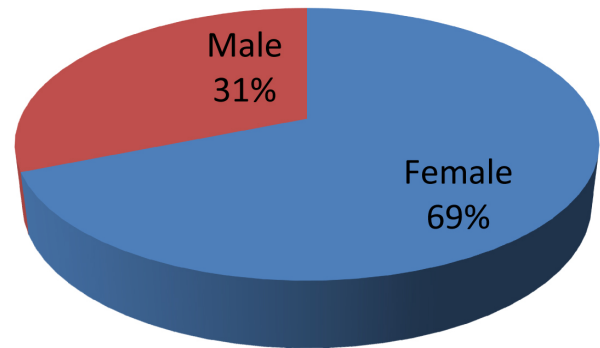

Figure 2. Gender representation in the study. 


\section{Total sum of trees}

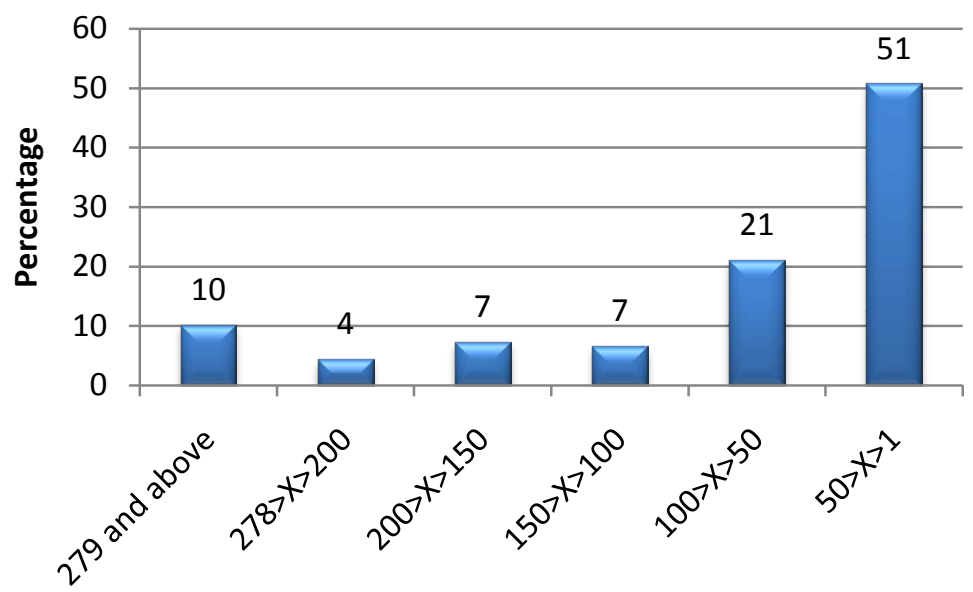

Figure 3. Showing range of total sum of trees per farmer. T-test calculations; $\mathrm{H}_{0}:$ Most farms do not have ten (10) percent (\%) tree cover; $\mathrm{H}_{1}$ : Most farms have ten (10) percent (\%) tree cover.

\begin{tabular}{|c|c|c|c|c|c|}
\hline & \multirow[b]{2}{*}{$\mathrm{T}$} & \multirow[b]{2}{*}{$d f$} & \multirow{2}{*}{$\begin{array}{l}\text { Mean } \\
\text { Difference }\end{array}$} & \multicolumn{2}{|c|}{$\begin{array}{l}95 \% \text { Confidence } \\
\text { Interval of the } \\
\text { Difference }\end{array}$} \\
\hline & & & & Lower & Upper \\
\hline Trees & -11.611 & 137 & -169.080 & -197.87 & -140.29 \\
\hline
\end{tabular}

Figure 4. T-test calculations.

Figures 5-11 show photos of the farmlands in the study area.

\section{Discussion}

Farmers are working towards achieving ten percent tree cover in their farms by either planting trees or conserving natural trees in their farms. This has been occasioned by the fact that trees are another source of income. For instance Mangifera indica (fruit trees) are a reliable source of income due to their drought tolerant characteristic that enables it to do well even during drought years. Pruning the trees also produces mulch which decomposes thus increasing soil fertility of the farm, thus use less or no fertilizer, and hence reducing the direct emissions of $\mathrm{N}_{2} \mathrm{O}$ and indirect greenhouses gasses (GHGs) emissions created through fertilizer production. Therefore, agroforestry is an inexpensive way of maintaining soil fertility. It also helps in controlling soil erosion, combat leaching of minerals and improving microclimate. Trees improve microclimate through maintaining safe levels of oxygen and carbon dioxide. They remove carbon from atmosphere and use it for photosynthesis; thus reducing GHGs. Trees such as Acacia tortilis are paramount in providing fodder (fruits) for 


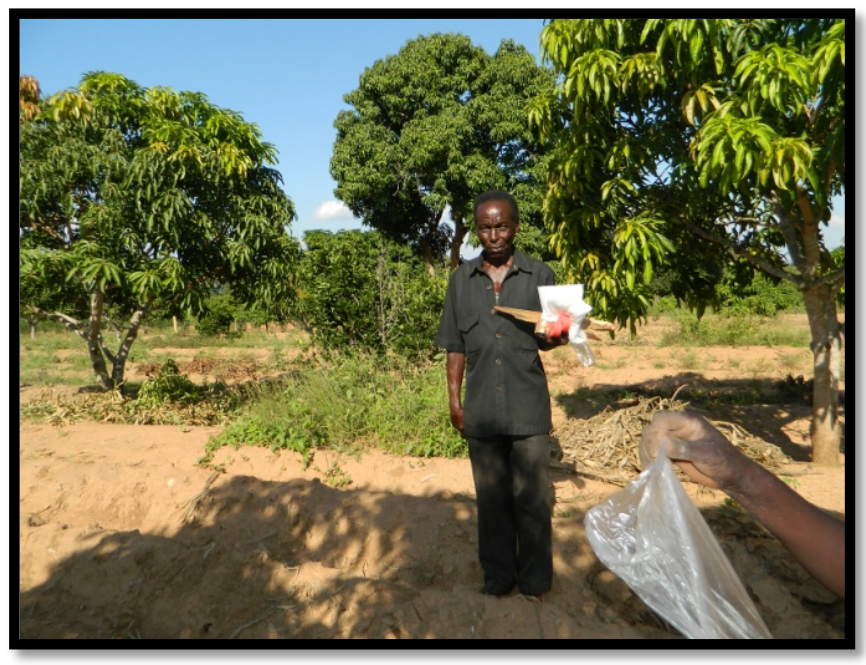

Figure 5. Farm with Mangifera indica trees (source photo by Dickson, 2014).

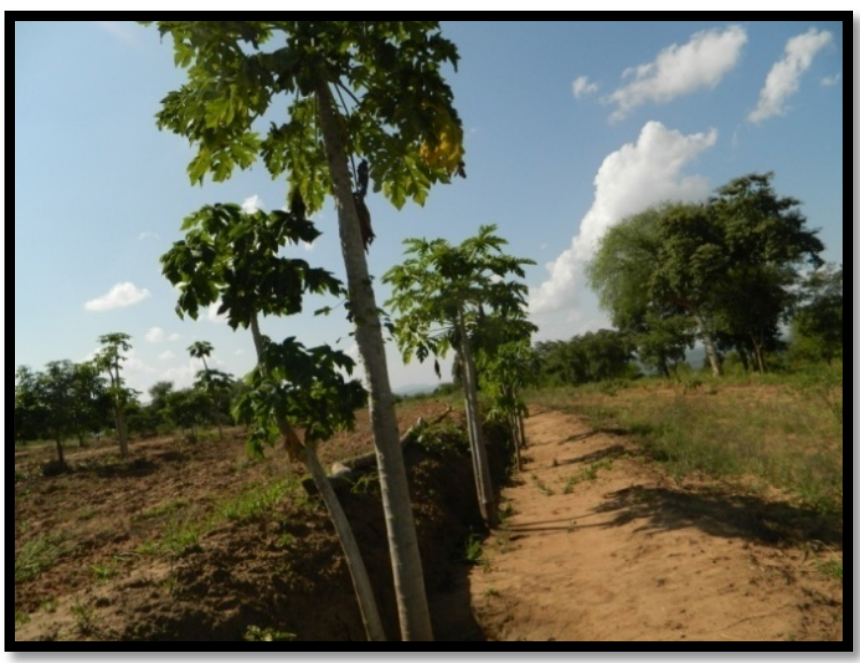

Figure 6. Farm with Carica papaya trees (source photo by Dickson, 2014).

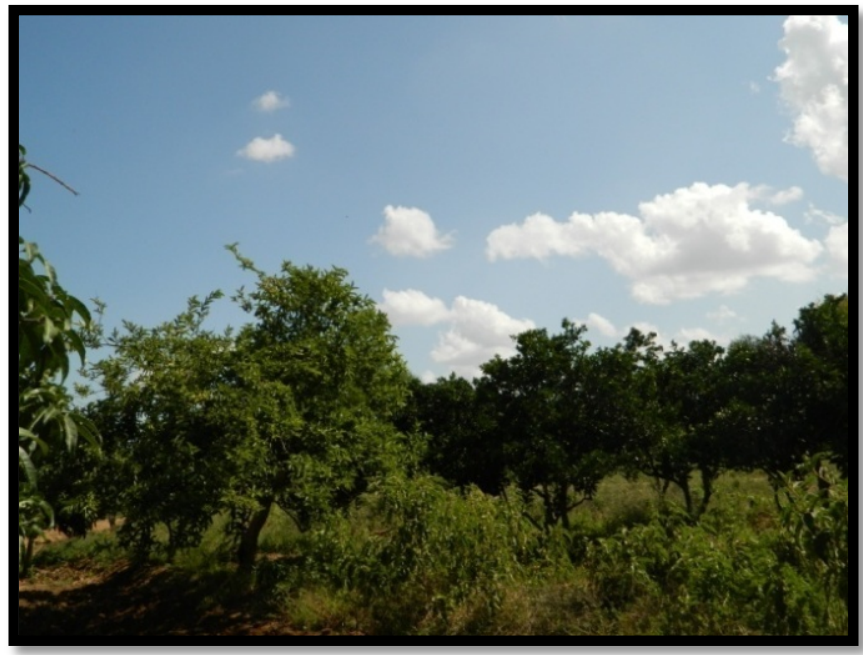

Figure 7. Farm with Citrus sinensis trees (source photo by Dickson, 2014). 


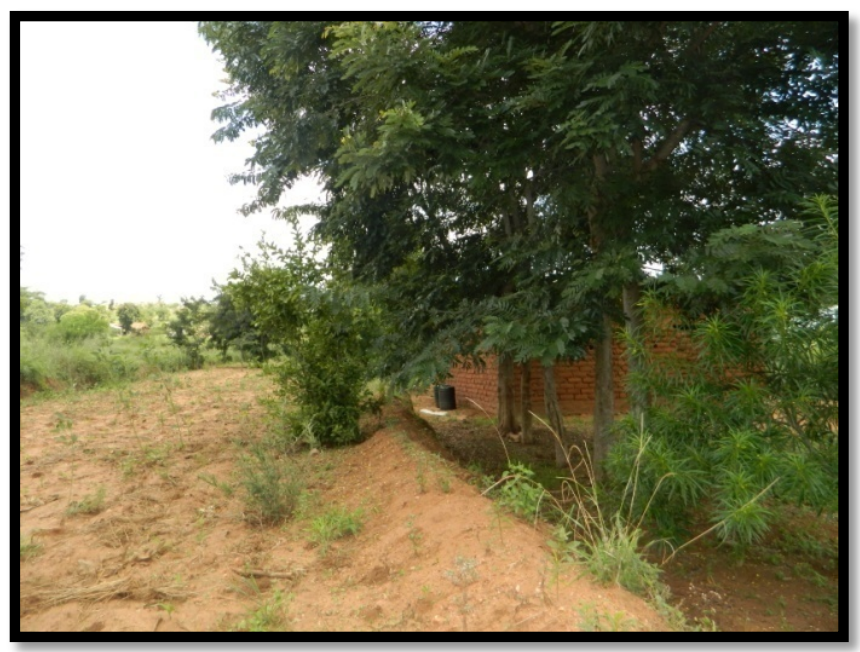

Figure 8. Farm with Senna siemea trees (Source photo by Dickson, 2014).

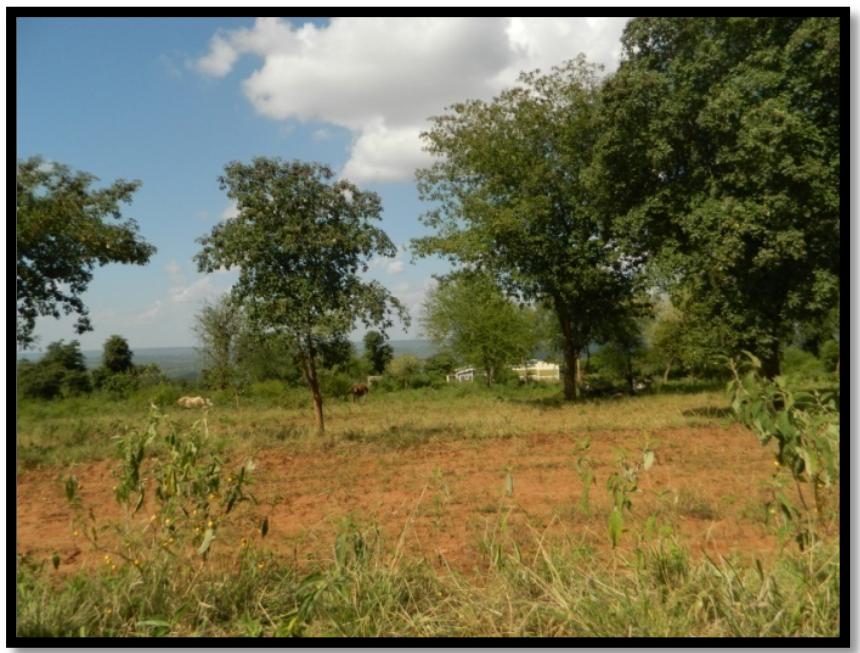

Figure 9. Farm with Terminalia brownie trees (Source photo by Dickson, 2014).

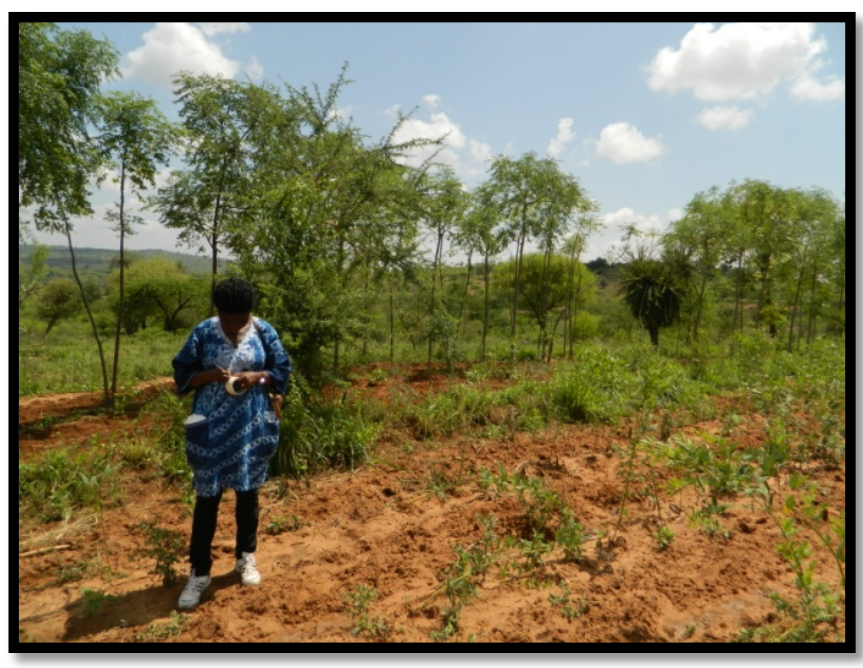

Figure 10. Farm with Melia volkensii trees (Source photo by Dickson, 2014). 


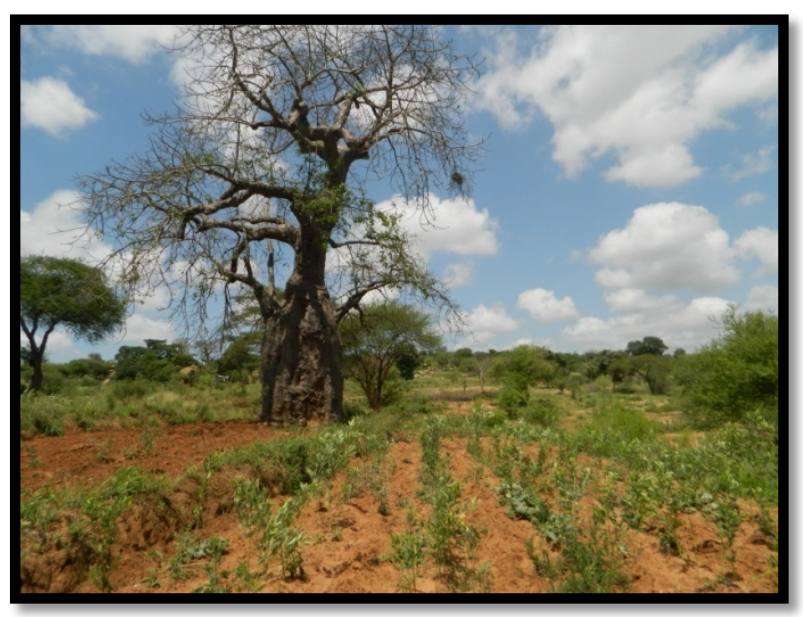

Figure 11. Farm with Adansonia digitata tree (Source photo by Dickson, 2014).

livestock. Farmers have therefore invested in harvesting Acacia tortilis fruits to either use them by feeding to their livestock or sell to other farmers and thus generating income.

\section{Recommendations}

Some trees harbor crop pests thus the necessary to train farmers on the species of trees that will coexist with crops. For instance where Sesbania sesban is grown there is usually a lot of nematodes and thus crops that are sensitive to nematodes should not be grown near them. It is of paramount importance that farmers be supplied with seedlings that are drought resistant. This can be achieved through establishment of tree nurseries for drought resistant trees in the area.

\section{Conflicts of Interest}

The author declares no conflicts of interest regarding the publication of this paper.

\section{References}

[1] Reid, A.S. Ten percent Multipurpose Tree Cover for Every Farm: A Low Risk, High Opportunity First Step.

https://www.researchgate.net/publication/254676571_Ten_percent_multipurpose_t ree_cover_for_every_farm_A_low_risk_high_opportunity_first_step

[2] (2009) Agriculture (Farm Forestry) Rules.

[3] Nair, P.R. (1993) An Introduction to Agroforestry. Kluwer Academic Publishers, Dordrecht.

[4] http://jkuates.co.ke/MANGO_CULTIVATION_IN_KENYA.pdf 